\title{
Conditioning of a statistical indicator for the detection of an asynchronous machine rotor faults
}

\author{
Nabil NGote ${ }^{1, a}$, SaÏd Guedira ${ }^{1}$ and Mohamed Cherkaoui ${ }^{2}$ \\ 1 Laboratoire CPS2I (Commande, Protection et Surveillance des Installations Industrielles), ENIM (École Nationale \\ de l'Industrie Minérale), BP 753, Agdal, Rabat, Maroc \\ 2 Équipe de Recherche en Machines Électriques, EMI (École Mohammadia d'Ingénieurs), BP 765, Agdal, Rabat, Maroc
}

Received 21 December 2011, Accepted 23 June 2012

\begin{abstract}
In this paper, the cyclostationary characteristics of electrical signals will be exploited in order to detect the rotor faults of an asynchronous machine. These defects are the most complex in terms of detection since they interact with the $50 \mathrm{~Hz}$ carrier with a weak band occupied in frequency. The testing ground used includes an industrial three-phase wound rotor asynchronous motor of $400 \mathrm{~V}, 6.2 \mathrm{~A}, 50 \mathrm{~Hz}$, $3 \mathrm{~kW}, 1385 \mathrm{rpm}$ characteristics. The rotor fault has been carried out by adding an extra $40 \mathrm{~m} \Omega$ resistance on one of the rotor phases (i.e. $10 \%$ of the rotor resistance value per phase, $R_{r}=0.4 \Omega$ ). From the stator voltage and current acquisition, and by application of the Time Synchronous Averaging (TSA) method to the stator current, the electrical signal will be conditioned in order to obtain a sensitive indicator allowing to easily distinguish the healthy cases from defective ones.
\end{abstract}

Key words: Cyclostationarity / time synchronous averaging (TSA) / monitoring / rotor fault / asynchronous motor

\begin{abstract}
Résumé - Conditionnement d'un indicateur statistique pour la détection de défauts rotoriques d'une machine asynchrone. Dans cet article, les caractéristiques cyclostationnaires des signaux électriques vont être exploitées pour détecter les défauts rotoriques d'une machine asynchrone. Ces derniers, sont les plus complexes au niveau de la détection car ils interagissent avec la porteuse à $50 \mathrm{~Hz}$ avec une faible bande occupée en fréquence. Le banc d'essai utilisé comprend un moteur asynchrone triphasé industriel à rotor bobiné, de caractéristiques $400 \mathrm{~V}, 6,2 \mathrm{~A}, 50 \mathrm{~Hz}, 3 \mathrm{~kW}, 1385 \mathrm{tr}^{\mathrm{min}}{ }^{-1}$ et le défaut rotorique est réalisé par adjonction d'une résistance additionnelle de $40 \mathrm{~m} \Omega$ sur une des phases du rotor (soit $10 \%$ de la valeur de la résistance rotorique par phase $R_{r}=0,4 \Omega$ ). À partir de l'acquisition des signaux électriques (tension et courant) et par application de la méthode de Moyennage Synchrone (TSA : Time Synchronous Averaging) au courant statorique, le signal électrique sera conditionné afin d'obtenir un indicateur sensible permettant de distinguer aisément les cas sain et défectueux de la machine.
\end{abstract}

Mots clés : Cyclostationnarité / moyennage synchrone / surveillance / défaut rotorique / moteur asynchrone

\section{Introduction}

The electrical drives using asynchronous machines are very common within industrial applications due to their low costs, high performance and robustness. However, there are various reasons, related to the stator or rotor, which can sometimes affect the well-functioning of

\footnotetext{
${ }^{\mathrm{a}}$ Corresponding author: ngotenabil@gmail.com
}

these machines [1-3]. The appearance of a fault in the drive modifies its operation, which affects its performance. There are mainly two approaches for the monitoring of the electrical-drive system: the mechanic's, based on the vibration, speed and torque measures and the electrotechnician's, based on the current and voltage measures.

Within a predictive maintenance framework, the proposed method is dedicated to the monitoring of asynchronous machines based on a statistical approach by 


\section{Nomenclature}

\begin{tabular}{|lll|}
\hline$f_{\text {samp }}$ & $(\mathrm{Hz})$ & Sampling rate $(25.6 \mathrm{kHz}$ in this paper $)$ \\
$I_{\text {res }}(t)$ & $(\mathrm{A})$ & Residual current \\
$I_{\text {resRMS }}$ & $(\mathrm{A})$ & Residual current RMS \\
$I_{\mathrm{s}}(t)$ & $(\mathrm{A})$ & Stator current \\
$I_{\text {savg }}(t)$ & $(\mathrm{A})$ & Synchronous averaged current \\
$I_{\mathrm{sh}}(t)$ & $(\mathrm{A})$ & Stator-current harmonic component \\
$I_{\text {smec }}(t)$ & $(\mathrm{A})$ & Mechanical-structure-related stator current \\
$I_{\text {srand }}(t)$ & $(\mathrm{A})$ & Stator-current random component \\
$I_{\text {sRMS }}$ & $(\mathrm{A})$ & Stator current RMS \\
$N$ & & Number of samples \\
$N_{\text {samp }}$ & & Number of samples $(512$ per period in this paper $)$ \\
$T_{\text {samp }}$ & $(\mathrm{s})$ & Sampling period $\left(T_{\text {samp }}=1 / f_{\text {samp }}\right)$ \\
\hline
\end{tabular}

development of an indicator resulting from the electrical signals of the machine (current and voltage). Indeed, the current signal presents a nonstationary behavior related to the machine operating process and the electrical phase fluctuations [4]. Very little work has been done to exploit the electrical-signal cyclostationary characteristics [4], and it seems interesting to adapt these signal treatment tools to the electrical signal case. We are particularly interested in the rotor failures. Those generally lead to an increase of a one-phase rotor resistance value $[1,2,5-$ 7]. Therefore, a rotor defect has been created by adding a $10 \%$ value extra resistance on one phase of the rotor, and acquired the stator voltage and current signals.

A simple comparison between the stator current RMS in the healthy and defective modes of the no-load machine does not allow us to detect the failure (the variation is about $1 \%$ only). The stator current RMS cannot thus be used as a sensitive rotor defect indicator. A preliminary conditioning of this indicator will precisely make it possible to exploit the stator current cyclostationarity. By application of the TSA method $[8,9]$, the residue related to the machine mechanics is obtained by subtraction. After conditioning, the new energy indicator will allow the easy distinction of the healthy and defective cases (the variation of the indicator value being clearly higher).

\section{Cyclostationarity}

\subsection{Strict-sense stationarity}

Strictly speaking, it is said that a random process $\{x(t)\}$ is stationary [10] if its statistical properties are invariant by translation in time, particularly its probability density:

$$
\begin{aligned}
& p\left(x_{1}, \ldots \ldots \ldots, x_{n} ; t_{1}, \ldots \ldots \ldots, t_{n}\right) \\
& \quad=p\left(x_{1}, \ldots \ldots, \ldots, x_{n} ; t_{1}+\tau, \ldots \ldots, t_{n}+\tau\right)
\end{aligned}
$$

for all $n$, for all $\tau$ and for any vector time $\left\{t_{i}\right\}_{i=1, \ldots, n}$; $\left\{x_{i}\right\}_{i=1, \ldots, n}$ being a realization.

So every moment of this random process is invariant by temporal translation.

\subsection{Wide-sense stationarity}

Broadly speaking, a random process is stationary if:

- Its average is constant:

$$
m_{x}(t)=m_{x}
$$

- Its covariance function depends only on the temporal variation:

$$
K_{x}\left(t_{1}, t_{2}\right)=K_{x}(\tau) \quad \text { where } \quad \tau=t_{1}-t_{2}
$$

When the process is not stationary, its probability density can vary randomly. A very particular class of nonstationary signals is referred to as the cyclostationary signals. A signal is known to be cyclostationary [11] if periodicities are found in some of its statistics. Thus, each period (or cycle) of this signal could be regarded as the realization of the same random process.

\subsection{Strict-sense cyclostationarity}

A random process $\{x(t)\}$ is known as strict-sense cyclostationary, of $T$ cycle, if its probability density is periodic of $T$ period:

$$
\begin{aligned}
& p\left(x_{1}, \ldots \ldots \ldots, x_{n} ; t_{1}, \ldots \ldots \ldots, t_{n}\right) \\
& \quad=p\left(x_{1}, \ldots \ldots \ldots, x_{n} ; t_{1}+T, \ldots \ldots, t_{n}+T\right)
\end{aligned}
$$

\subsection{First-order cyclostationarity}

The basic, or first-order, cyclostationary signal is the one with a $T$-period moment of order 1 (or average):

$$
m_{x}(t)=E\{x(t)\}=m_{x}(t+T)
$$

$E\{x(t)\}$ is the overall statistical average (not to be confused with the temporal average). In practice, only one realization is often available, so the overall average is replaced with a cycle average called synchronous average [4]. 


\subsection{Second-order cyclostationarity}

A second-order cyclostationary signal is a signal whose 2nd order moments are periodic. In particular, the function of autocorrelation $C_{x}(t, \tau)$ is a $T$-periodic function:

$$
C_{x}(t, \tau)=E\left\{x(t) x^{*}(t-\tau)\right\}=C_{x}(t+T, \tau+T)
$$

where $x^{*}(t)$ is the transposed conjuguate of $x(t)$.

\subsection{Wide-sense cyclostationarity}

Wide-sense cyclostationary signals are the signals which are both first and second order cyclostationary.

\section{Signal synchronization}

The asynchronous motor operating process and the electric supply fluctuations cause the non-stationary behavior of the stator current signal. Previous research [1214] has applied time/frequency representation techniques with an aim of identifying the signatures of the faults not in the frequential field, but in the time/frequency domain.

However, there has been very little work [4] exploiting the electrical-signal cyclostationary characteristics to identify the faults which occur in an asynchronous-motor drive. The idea is to extend the application of these signalprocessing tools to the case of electrical signals.

In this work, the first-order cyclostationarity of stator current and voltage is largely exploited. However a problem of cycle drift from one electric cycle to another occurs, due to the electrical supply fluctuations. Figure 1 represents the superposition of 1000 electric cycles acquired in a temporal way and it clearly illustrates the shift between the 1 st and the 1000th voltage signal cycle. The sampling rate taken is $25.6 \mathrm{kHz}$, so the number of samples per average cycle of $50 \mathrm{~Hz}$ is $512(25600 / 50=512)$.

The cyclic statistic rules cannot be directly applied to these signals to extract desired information, except if a way to compensate these fluctuations is proposed.

A preliminary stage is needed: the current and voltage signals must be re-sampled according to a reference which "follows" these fluctuations: it's "the synchronization of the current and voltage signals". Therefore, a re-sampling algorithm which allows synchronizing the acquired signals (stator current and voltage) is developed. Synchronization is operated by compensation of the delay between the various electric cycles.

The purpose is to synchronize all electric cycles according to the same reference, so all cycles must be superimposed after the synchronization process.

To do this, voltage signal is first cut out in slices, each one corresponding to one period $(T=20 \mathrm{~ms})$, and each period containing an integer number of samples $N_{\text {samp. }}$. In our case:

- The acquisition duration $T_{a}$ is $20 \mathrm{~s}$, so the number of voltage periods is $N=T_{a} / T=1000$;

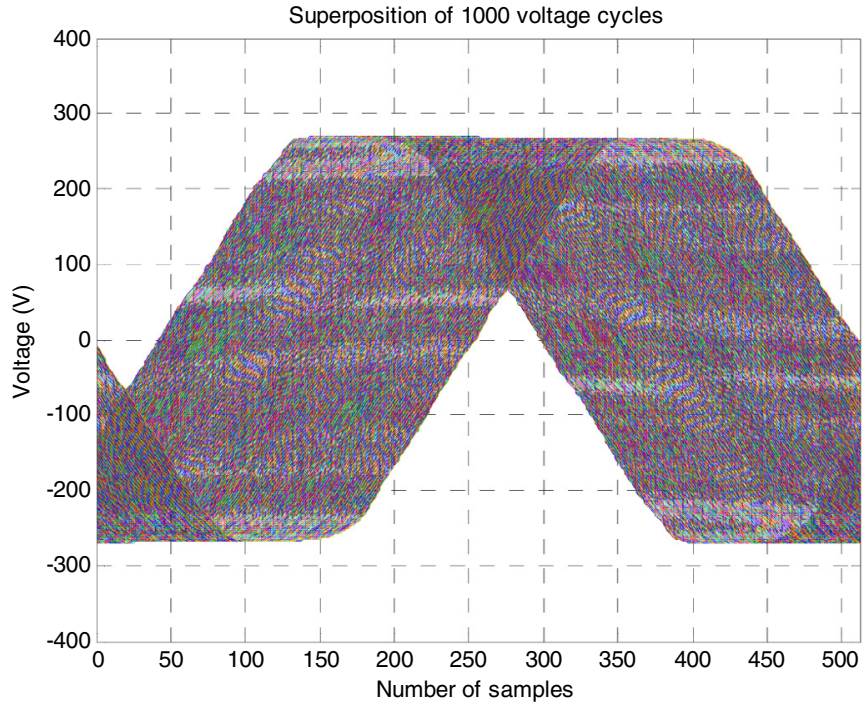

Fig. 1. 1000 voltage cycles before synchronization.

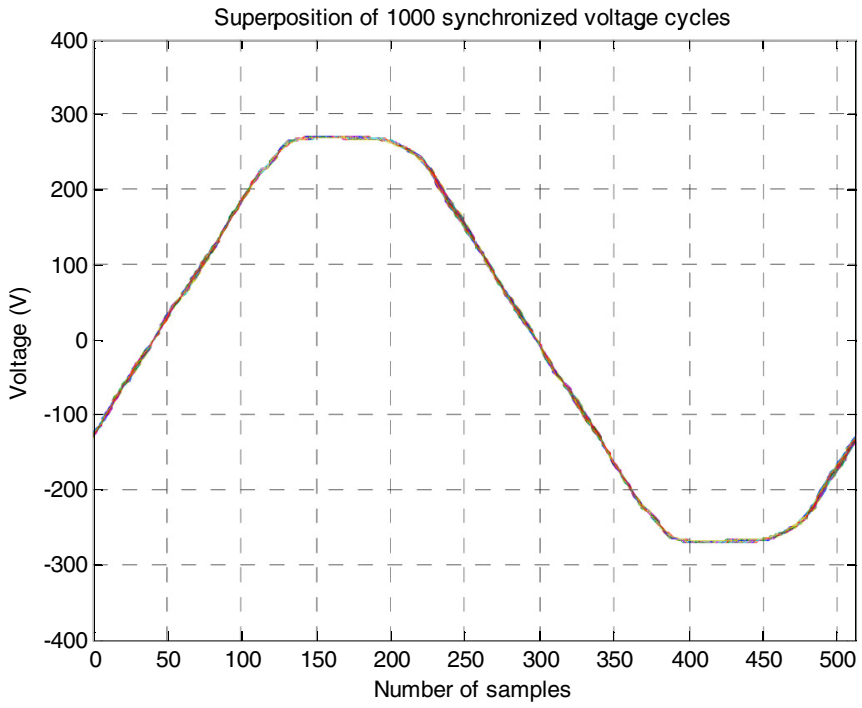

Fig. 2. 1000 voltage cycles after synchronization.

- The sample rate is $25.6 \mathrm{kHz}$, so $N_{\text {samp }}=512$ samples per period $(512=25.6 \mathrm{kHz} \times 20 \mathrm{~ms})$.

The shift between the first voltage period, taken as a reference, and the others is estimated: for this purpose, the first-period zero abscissa and the $k$ th-period zero abscissa (for $k=2$ to $N$ ) are determined; the shift corresponds to the difference between these two abscissas. Then, each period is shifted to make it coincide with the first one (reference). If the two periods are already synchronous, the shift is then null. The obtained signal is represented in Figure 2.

The current signal will be similarly synchronized; but by using the voltage-shift values: the fluctuations due to the supply frequency will be compensated.

Figures 3 and 4 illustrate the superposition of 1000 stator current cycles, respectively in healthy and defective cases before synchronization. 


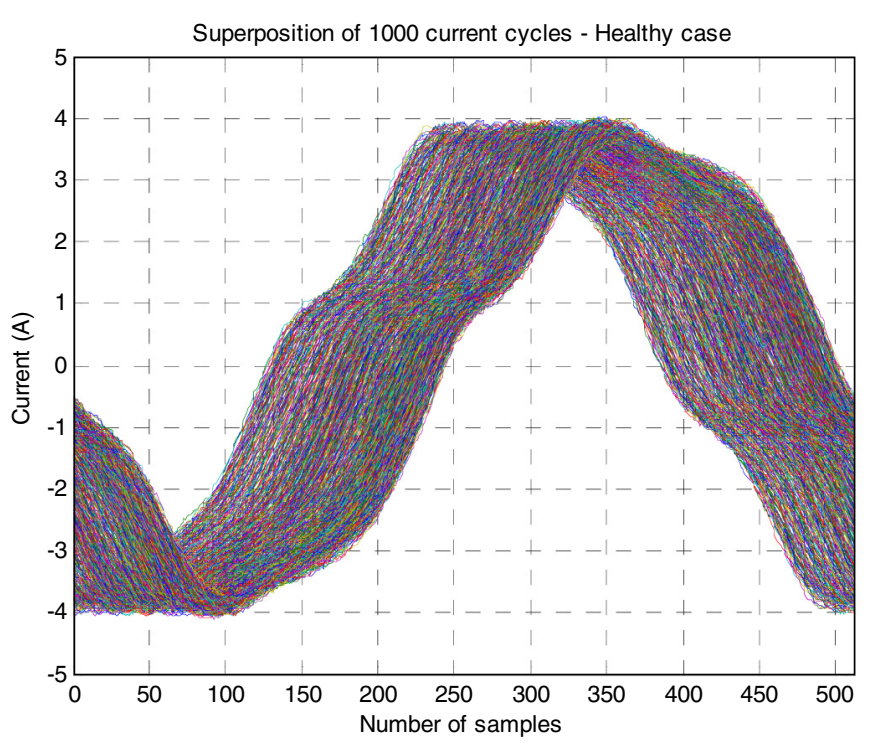

Fig. 3. 1000 current cycles - healthy case (before synchronization).

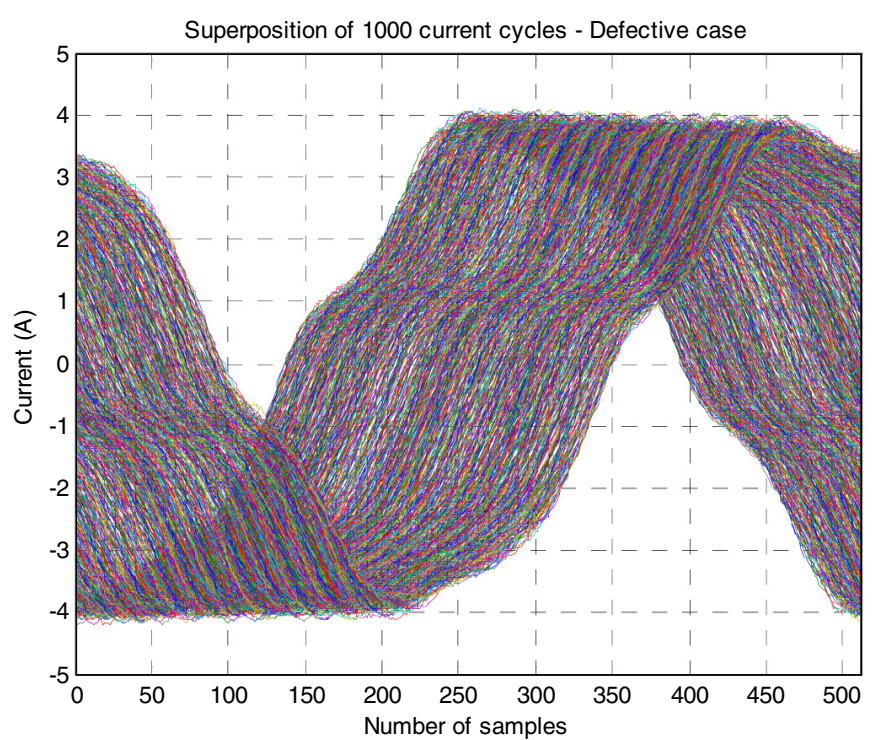

Fig. 4. 1000 current cycles - defective case (before synchronization).

Figures 5 and 6 show the superposition of 1000 synchronized stator current cycles respectively in healthy and defective cases.

Once all cycles are synchronized, the signal is rebuilt by setting these cycles end to end. Figure 7 illustrates synchronized current in healthy (a) and faulty (b) cases.

All cycles are now synchronous and the "synchronous averaging" can be carried out.

\section{Time Synchronous Averaging (TSA)}

A rotor fault can be detected by highlighting a statorcurrent amplitude or phase modulation. However, the

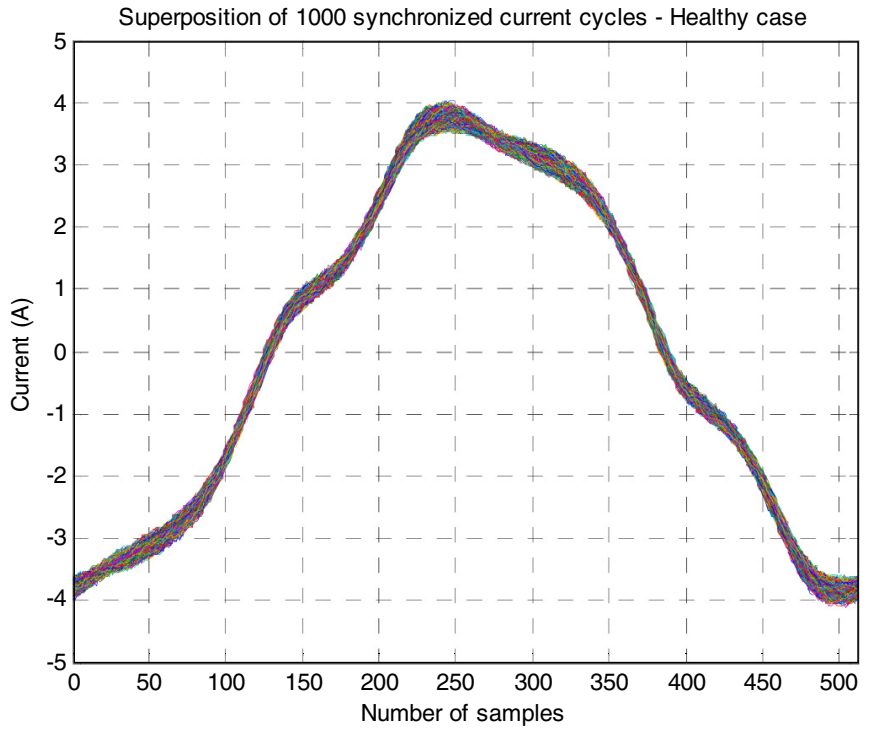

Fig. 5. 1000 current cycles - healthy case (after synchronization).

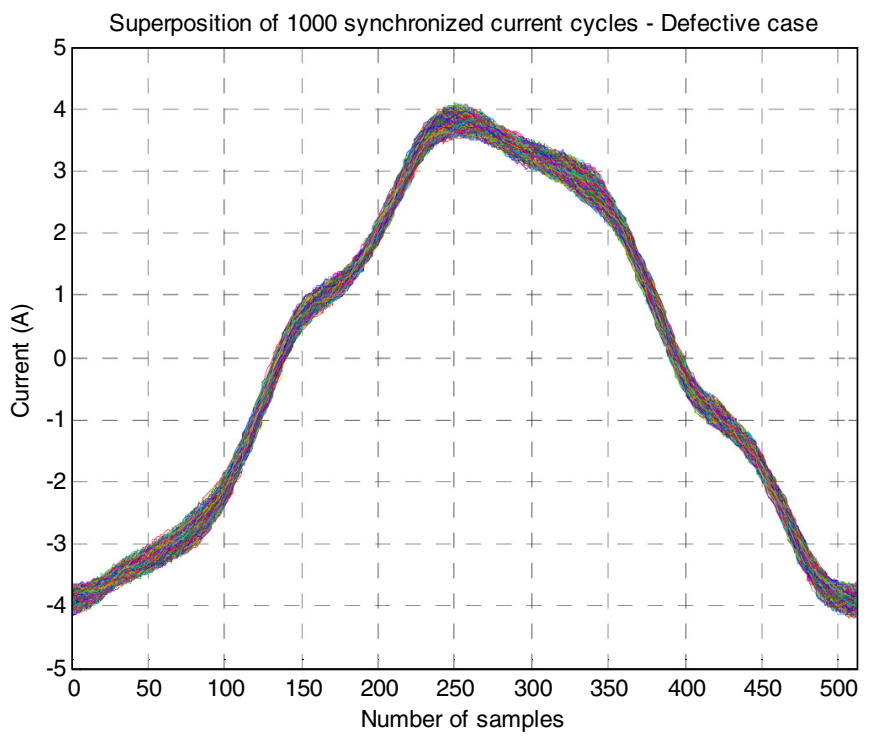

Fig. 6. 1000 current cycles - defective case (after synchronization).

modulated-signal weak frequency band makes it too difficult to detect modulation. An alternative to overcome this difficulty is proposed by [8]: the Time Synchronous Averaging (TSA) method. It's a way to reshape the signal before its processing. The TSA method allows the separation between the excitation sources and, consequently, fault identification.

The stator current $I_{s}(t)$ can be decomposed as follows:

$$
I_{s}(t)=I_{s_{h}}(t)+I_{s_{\text {mec }}}(t)+n(t)
$$

where $I_{s_{h}}(t), I_{s_{\text {mec }}}(t)$ and $n(t)$ are respectively the stator-current harmonic component, the mechanicalstructure-related stator current and the noise. 


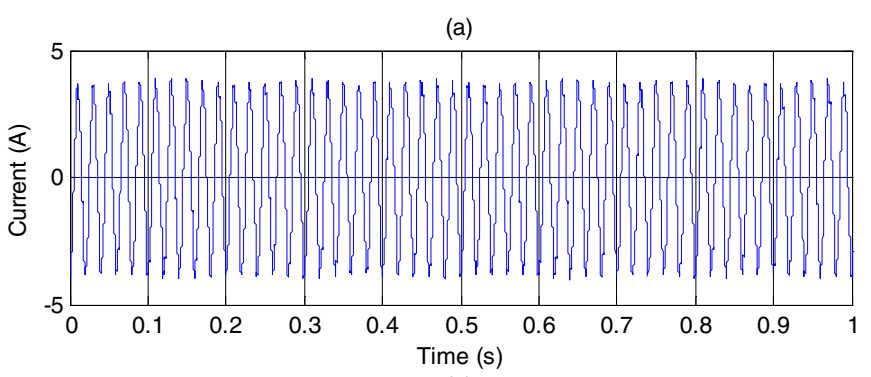

(b)

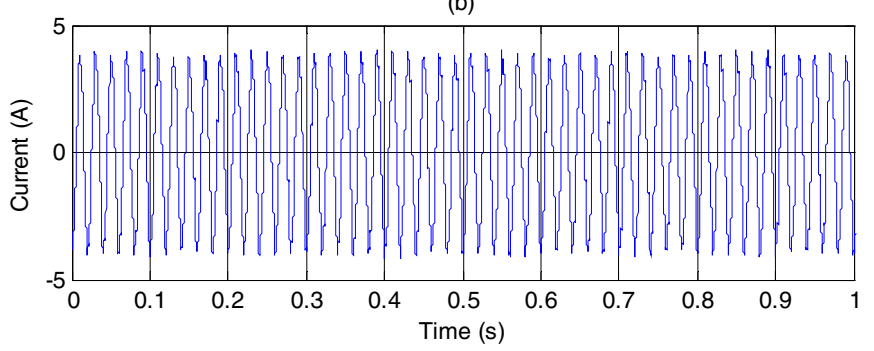

Fig. 7. Synchronized stator current. (a) Healthy case. (b) Defective case.

In fact, the asynchronous motor monitoring consists of supervising the signal harmonic part. So the harmonic frequency $(50 \mathrm{~Hz})$ which is related to electrical phenomena and the mechanical structure-related frequency must be separated.

For this purpose, the TSA method will be applied to the stator current. In fact, the stator current is the sum of a determinist signal $\left(I_{s_{h}}(t)\right)$ and a random signal (sum of $I_{s_{\text {mec }}}(t)$ and $\left.n(t)\right)$; whose average value is zero:

$$
I_{s}(t)=I_{s_{h}}(t)+I_{s_{\text {rand }}}(t)
$$

$I_{s_{\text {rand }}}(t)$ is the stator-current random component.

The synchronous averaging of $N$ stator-current samples for each sample time $n$ is done by:

$$
I_{s_{\text {avg }}}^{N}\left(n \bullet T_{\text {samp }}\right)=\frac{1}{N} \sum_{k=1}^{k=N} I_{s}^{k}\left(n \bullet T_{\text {samp }}\right)
$$

where:

$-T_{\mathrm{samp}}=\frac{1}{f_{\mathrm{samp}}}$, where $f_{\mathrm{samp}}$ is the sampling rate $(25.6 \mathrm{kHz})$;

$-I_{s}^{k}$ is the $k$ th synchronized stator current cycle;

$-n$ is the sample row $(n=1$ to $512 ; 512=25.6 \mathrm{k} / 5$;

512 is the number of samples per $50 \mathrm{~Hz}$ cycle).

For the large value of $N$

$$
\lim _{N \rightarrow \infty} I_{s_{\text {avg }}}^{N}(t)=I_{s_{h}}(t)
$$

Note that only the harmonic part $I_{s_{h}}(t)$ corresponding to $50 \mathrm{~Hz}$ frequency remains in the averaged signal; since the random-component average value is zero.

Thus, the synchronous averaging allows an effective separation between electrical-related and mechanicalrelated components.

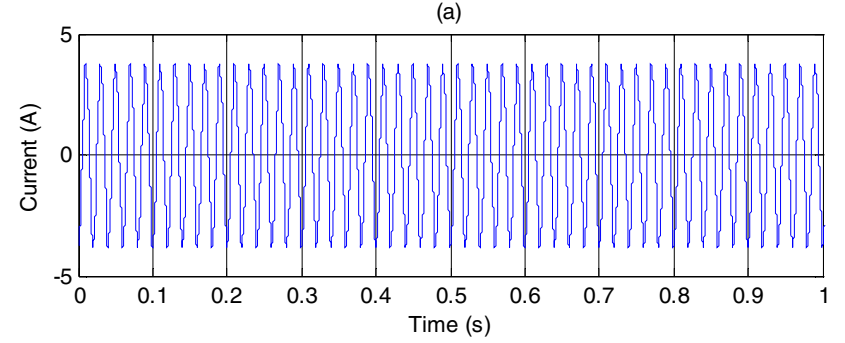

(b)

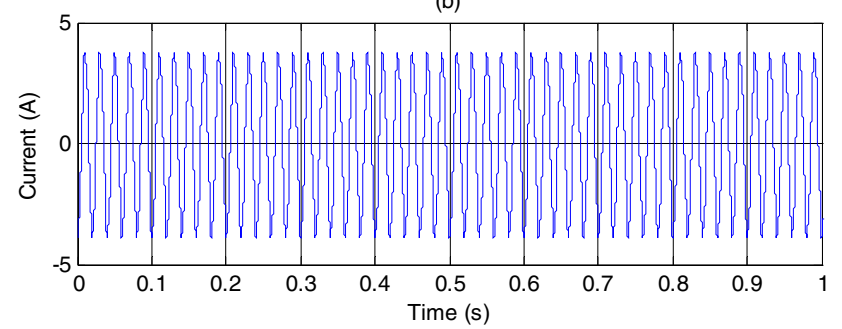

Fig. 8. TSA stator current. (a) Healthy case. (b) Defective case.

The subtraction between the stator current $I_{s}(t)$ and the synchronous averaged current $I_{s_{\mathrm{avg}}}^{N}(t) \approx I_{s_{h}}(t)$ (for the large value of $N)$ gives the residual current $I_{\text {res }}(t)=$ $I_{s_{\text {rand }}}(t)$ where only mechanical-related frequencies remain.

The TSA current has the same shape as the current signal. Figures $8 \mathrm{a}$ and $\mathrm{b}$ respectively show the healthy and defective TSA currents.

The residual signal is obtained by subtraction of the TSA signal from the synchronized signal. This action reduces the electrical contribution, and, consequently, makes the extraction of mechanical-related information easier.

\section{Conditioning of an indicator}

We are now interested in signal conditioning for the development of an asynchronous motor monitoring indicator. Three tests are carried out:

- test $\mathrm{n}^{\circ} 1$ : No-loaded motor. This particular case allows the detection of an inherent motor fault, without load influence;

- test $\mathrm{n}^{\circ} 2$ : Motor with a $65 \%$ nominal load;

- test $n^{\circ} 3$ : Full-loaded motor.

The simple comparison of the stator current RMS in the healthy and defective modes does not allow us to detect the failure. Indeed, in the first 2 tests, there is practically no difference; whereas in the 3rd test, this difference is of hardly $8 \%$. A first indicator $K_{1}$ is defined, such as the stator current RMS, according to the relation:

$$
K_{1}=\frac{I_{s_{\mathrm{RMS}}}(\text { healthy })-I_{s_{\mathrm{RMS}}}(\text { defective })}{I_{s_{\mathrm{RMS}}}(\text { healthy })}
$$

Table 1 recapitulates the values for the 3 tests.

There is too little variation of the $K_{1}$ indicator between the healthy and defective cases. It cannot be used 
Table 1. Stator current RMS values - healthy \& defective cases.

\begin{tabular}{|c|c|c|c|}
\hline & \multicolumn{2}{|c|}{ Stator current RMS } & \multirow{2}{*}{$K_{1}$ indicator } \\
\hline & Healthy case & Faulty cas & \\
\hline Test $\mathrm{n}^{\circ} 1$ & $2.61 \mathrm{~A}$ & $2.63 \mathrm{~A}$ & $1.05 \%$ \\
\hline Test $n^{\circ} 2$ & $3.72 \mathrm{~A}$ & $3.76 \mathrm{~A}$ & $1.25 \%$ \\
\hline Test $n^{\circ} 3$ & $5.58 \mathrm{~A}$ & $6.02 \mathrm{~A}$ & $7.93 \%$ \\
\hline
\end{tabular}

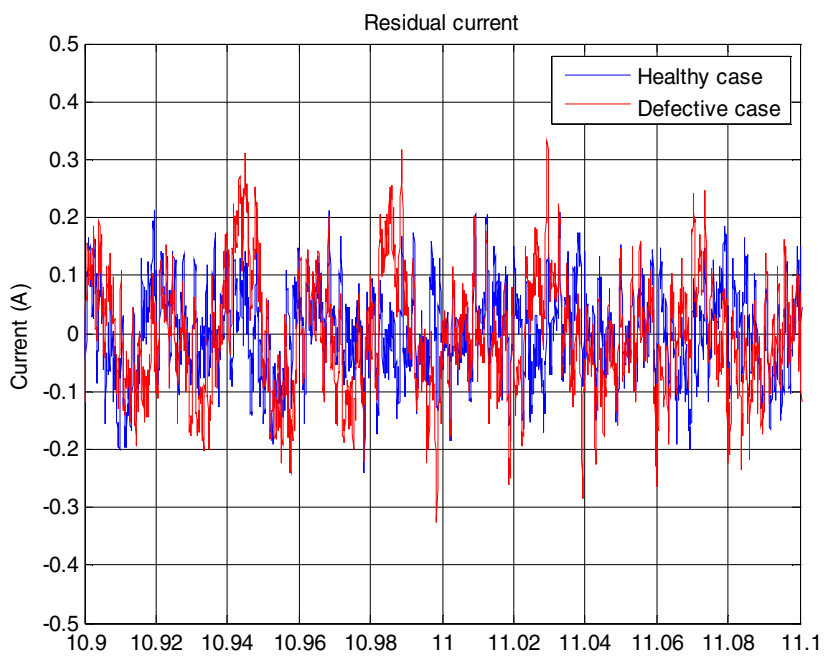

Fig. 9. No-loaded motor.

Table 2. Residual current RMS values - healthy \& defective cases.

\begin{tabular}{cccc}
\hline & \multicolumn{2}{c}{ Residual current RMS } & \multirow{2}{*}{$K_{2}$ indicator } \\
\cline { 1 - 3 } & Healthy case & Faulty cas & \\
\hline Test $\mathrm{n}^{\circ} 1$ & $0.0748 \mathrm{~A}$ & $0.0914 \mathrm{~A}$ & $22.07 \%$ \\
Test $\mathrm{n}^{\circ} 2$ & $0.1584 \mathrm{~A}$ & $0.3858 \mathrm{~A}$ & $143.6 \%$ \\
Test $\mathrm{n}^{\circ} 3$ & $0.2389 \mathrm{~A}$ & $0.8790 \mathrm{~A}$ & $267.9 \%$ \\
\hline
\end{tabular}

like a sensitive indicator of rotor defect. The idea now is to compare the residual current RMS obtained after the TSA of the stator current. The residual current RMS is calculated according to the relation:

$$
I_{\mathrm{res} \text { RMS }}=\sqrt{\frac{1}{N_{\mathrm{samp}}} \sum_{n=1}^{n=N_{\mathrm{samp}}} I_{\mathrm{res}}^{2}\left(n \bullet T_{\mathrm{samp}}\right)}
$$

where $N_{\text {samp }}$ corresponds to the number of current samples $\left(N_{\text {samp }}=512\right.$ samples per cycle $\times 1000$ cycles $=$ $512000)$.

Figures 9, 10 and 11 show the healthy and defective residual stator currents respectively for the 3 tests (no load, $65 \%$ nominal load and full load).

The electrical signal is conditioned in order to obtain a second indicator $K_{2}$, obtained from the residual stator current RMS, according to the relation:

$$
K_{2}=\frac{I_{\mathrm{res}_{\mathrm{RMS}}}(\text { healthy })-I_{\mathrm{res}_{\mathrm{RMS}}}(\text { defective })}{I_{\text {res }}}
$$

Table 2 recapitulates the values for the 3 tests.

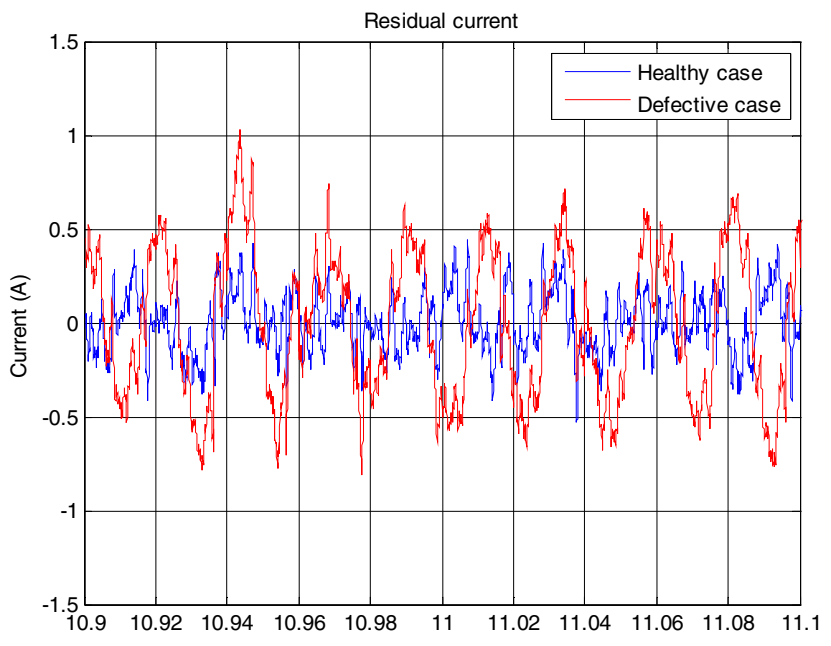

Fig. 10. Motor with a $65 \%$ nominal load.

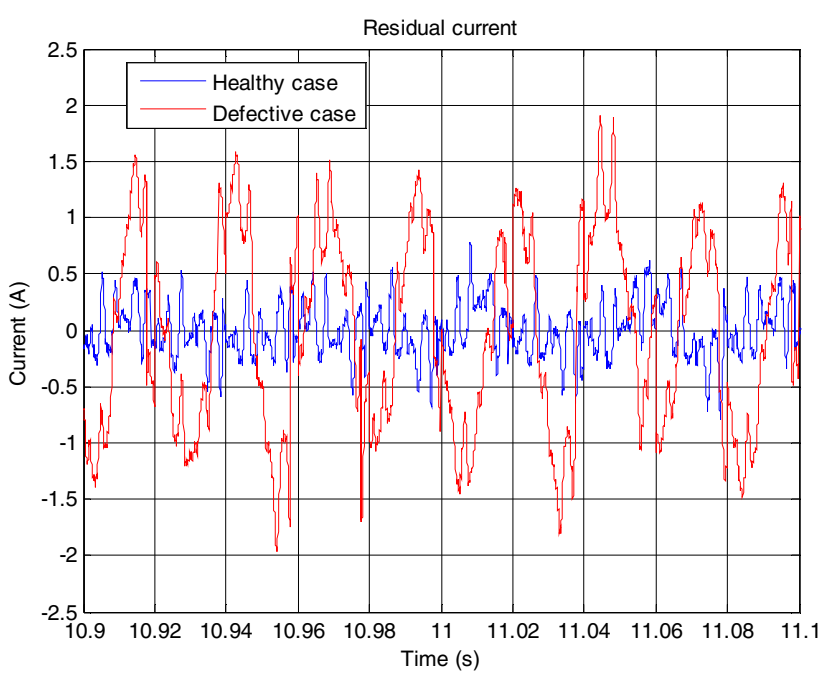

Fig. 11. Full loaded motor.

The conditioned indicator $K_{2}$, on the other hand, allows an easy distinction of the healthy and defective cases (the variation is from $22 \%$ for the no-loaded motor to nearly $270 \%$ in the case of a full-loaded motor).

\section{B Conclusion}

In this paper, the proposed method of asynchronousmotor-failure monitoring has two major advantages:

- First, it is a method which is based on the analysis of the "current" and "voltage" signals. We can therefore apply it even to the inaccessible engines (such as the engines immersed in the motor-driven pump groups), unlike the methods based on the analysis of the accelerometer signal, where a direct access to the engine is necessary to be able to place the sensors there.

- Besides, the approach is relatively simple: the monitoring of the residual current RMS makes it possible to clearly detect the defective case. In fact, with a 


\section{Appendix: Experimental device photos}

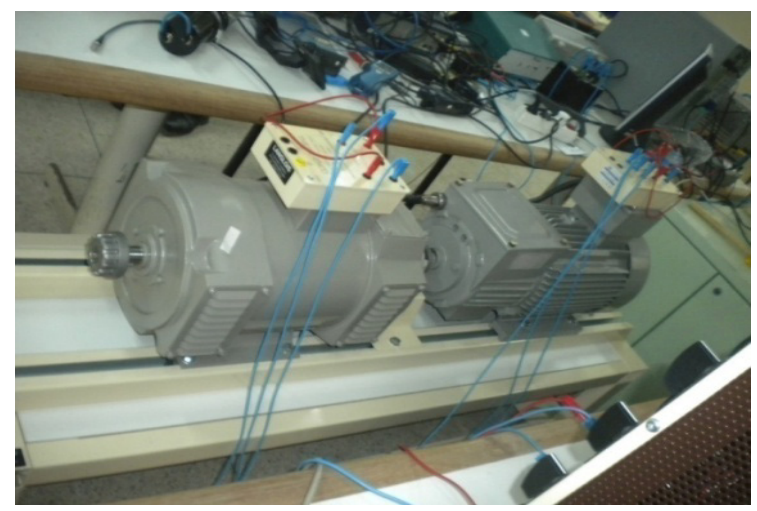

Fig. 12. Wound rotor asynchronous motor associated to DC generator.

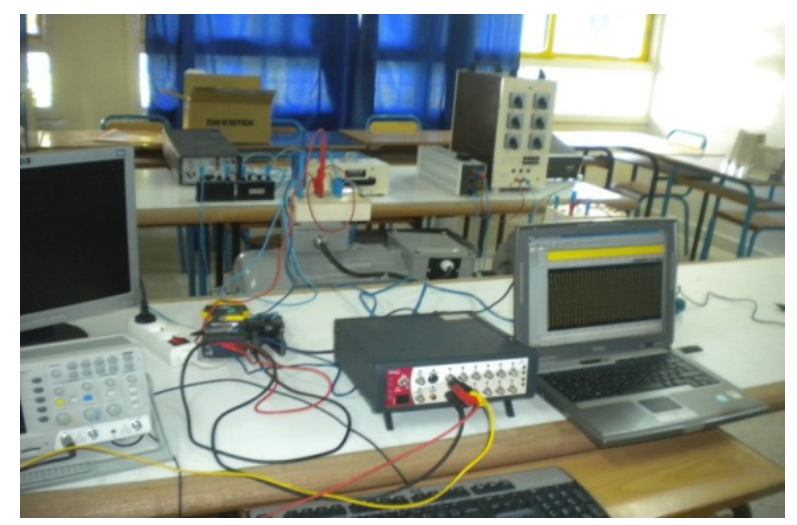

Fig. 14. Data acquisition system.

no-load engine, where the fault is hardest to detect, the $K_{2}$ indicator already shows a difference between healthy and faulty cases that exceeds $20 \%$, to go beyond $250 \%$ for the full-load engine case.

\section{References}

[1] H. Razik, Notes de cours sur le diagnostic de la machine asynchrone, IUFM de Lorraine, 2003

[2] O. Ondel, Diagnostic par reconnaissance des formes: Application à un ensemble Convertisseur - Machine asynchrone, Thèse, École Centrale de Lyon, 2006

[3] G. Didier, Modélisation et diagnostic de la machine asynchrone en présence de défaillances, Thèse, Université Henri Poincaré Nancy-I, 2004

[4] A. Ibrahim, Contribution au diagnostic de machines électromécaniques : Exploitation des signaux électriques et de la vitesse instantanée, Thèse, Université Jean Monnet, St-Étienne, 2009

[5] R. Fiser, S. Ferkolj, Modelling of dynamic performance of induction machine with rotor faults, In Procedings ICEM 1996, Vigo, Spain 1 17-22

[6] G. Didier, H. Razik, Sur la détection d'un défaut au rotor des moteurs asynchrones, Revue 3EI. 27 (2001) 53-62

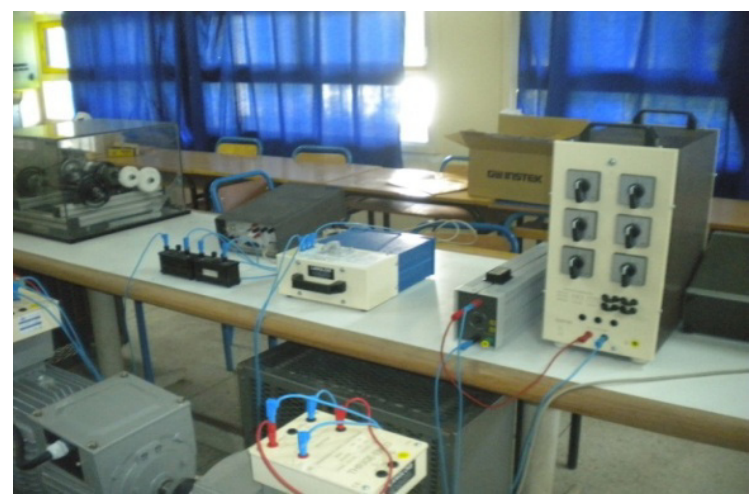

Fig. 13. Electrical load of the DC generator.

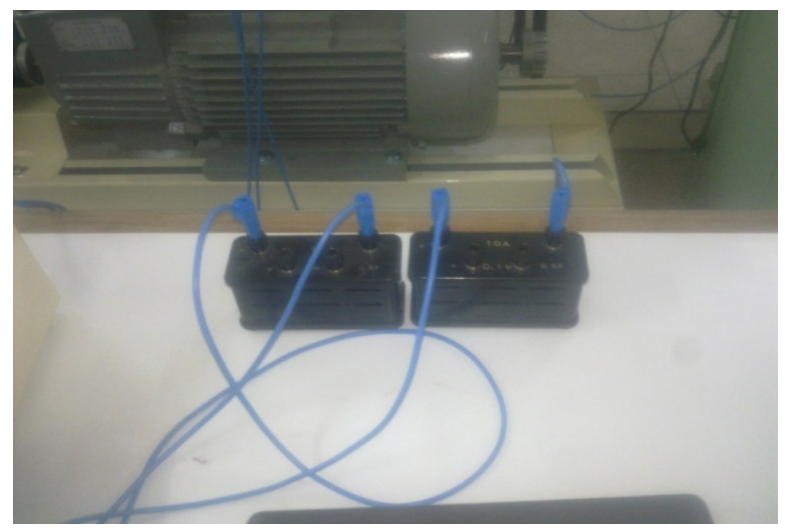

Fig. 15. Additional resistance (40 mohms).

[7] T. Boumégoura, H. Yahoui, G. Clerc, G. Grellet, Observation des paramètres du moteur asynchrone à cage d'écureuil avec un observateur non linéaire, Colloque EF'99, pp. 375-379, Lille 30\&31, mars 1999

[8] P.D. McFadden, J.D. Smith, A signal processing technique for detecting local defects in a gear from the signal average of the vibration, Proceedings of the Institution of Mechanical Engineers 199 (1985) 287-292

[9] P.D. McFadden, A revised model for the extraction of periodic waveforms by time domain averaging, Mechanical Systems and Signal Processing 1 (1987) 83-95

[10] W.R. Bennett, Statistics of regenerative digital transmission, Bell System Techn. J. 37 (1958) 1501-1542

[11] F. Bonnardot, Comparaison entre les analyses angulaire et temporelle des signaux vibratoires de machines tournantes. Étude du concept de cyclostationnarité floue, Thèse, Institut National Polytechnique de Grenoble, 2004

[12] M.E.H. Benbouzid, M. Vieira, C. Theys, Induction motors faults detection and localisation using stator current advanced signal processing techniques, IEEE Trans. Power Electronics 14 (1999) 14-22

[13] M.E.H. Benbouzid, G.B. Kliman, What stator current processing-based technique to use for induction motor rotor faults diagnosis? IEEE Trans. Energy Convers. 18 (2003) 238-244

[14] G. Salles, Surveillance et diagnostic des défauts de la charge d'un entraînement par machine asynchrone, Thèse, Université Lyon 1, 1997 